\title{
Evaluation of Angiopoietin-2 as a biomarker in gastric cancer: results from the randomised phase III AVAGAST trial
}

\author{
Ulrich T Hacker ${ }^{\star}, 1$, Laura Escalona-Espinosa ${ }^{2}$, Nicola Consalvo ${ }^{3}$, Valentin Goede ${ }^{4,5}$, Lars Schiffmann ${ }^{5,6}$, \\ Stefan J Scherer ${ }^{7}$, Priti Hedge ${ }^{8}$, Eric Van Cutsem ${ }^{9}$, Oliver Coutelle ${ }^{4,5,11}$ and Hildegard Büning ${ }^{2,10,11}$ \\ ${ }^{1}$ University Cancer Center Leipzig (UCCL), University Hospital Leipzig, Liebigstr. 20, Leipzig 04103, Germany; ${ }^{2}$ Center for Molecular \\ Medicine Cologne (CMMC), University of Cologne, Cologne, Germany; ${ }^{3}$ Biostatistics F. Hoffman-La Roche AG, Basel, Switzerland; \\ ${ }^{4}$ Department of Internal Medicine I, University Hospital Cologne, Cologne, Germany; ${ }^{5}$ Center of Integrated Oncology (ClO) \\ Cologne-Bonn, Cologne, Germany; ${ }^{6}$ Department of General, Visceral and Cancer Surgery, University Hospital Cologne, Cologne, \\ Germany; ${ }^{7}$ University of Wuerzburg, PCl, Biocenter, Am Hubland, Wuerzburg 97074, Germany; ${ }^{8}$ Oncology Early Clinical \\ Developement, Genentech, Inc., South San Francisco, CA, USA; ${ }^{9}$ University Hospital Gasthuisberg Leuven and KU Leuven, Leuven, \\ Belgium and ${ }^{10}$ Hannover Medical School, Institute of Experimental Hematology, Hannover, Germany
}

Background: In the phase III AVAGAST trial, the addition of bevacizumab to chemotherapy improved progression-free survival (PFS) but not overall survival (OS) in patients with advanced gastric cancer. We studied the role of Angiopoietin-2 (Ang-2), a key driver of tumour angiogenesis, metastasis and resistance to antiangiogenic treatment, as a biomarker.

Methods: Previously untreated, advanced gastric cancer patients were randomly assigned to receive bevacizumab $(n=387)$ or placebo $(n=387)$ in combination with chemotherapy. Plasma collected at baseline and at progression was analysed by ELISA. The role of Ang-2 as a prognostic and a predictive biomarker of bevacizumab efficacy was studied using a Cox proportional hazards model. Logistic regression analysis was applied for correlations with metastasis.

Results: Median baseline plasma Ang-2 levels were lower in Asian (2143 $\left.\mathrm{pg} \mathrm{ml}^{-1}\right)$ vs non-Asian patients $\left(3193 \mathrm{pg} \mathrm{ml}^{-1}\right), P<0.0001$. Baseline plasma Ang-2 was identified as an independent prognostic marker for OS but did not predict bevacizumab efficacy alone or in combination with baseline VEGF. Baseline plasma Ang-2 correlated with the frequency of liver metastasis (LM) at any time: Odds ratio per $1000 \mathrm{pg} \mathrm{ml}^{-1}$ increase: $1.19 ; 95 \% \mathrm{Cl} 1.10-1.29 ; P<0.0001$ (non-Asians) and 1.37; 95\% Cl 1.13-1.64; $P=0.0010$ (Asians).

Conclusions: Baseline plasma Ang-2 is a novel prognostic biomarker for OS in advanced gastric cancer strongly associated with LM. Differences in Ang-2 mediated vascular response may, in part, account for outcome differences between Asian and non-Asian patients; however, data have to be further validated. Ang-2 is a promising drug target in gastric cancer.

Gastric cancer is the second most frequent cause of cancer death in the world (Brenner et al, 2009; Jemal et al, 2011). There is substantial geographic variation in the incidence and mortality of gastric cancer, with the highest rates in East Asia and the lowest in
North America (Kamangar et al, 2006). Asian patients, however, appear to have increased survival rates compared with their Western counterparts (Bollschweiler et al, 1993). Nevertheless, survival rates are among the worst of any solid tumour despite

\footnotetext{
*Correspondence: Dr UT Hacker; E-mail: ulrich.hacker@medizin.uni-leipzig.de

${ }^{11}$ These authors share last authorship.
}

Received 25 September 2015; revised 29 December 2015; accepted 20 January 2016; published online 31 March 2016

(c) 2016 Cancer Research UK. All rights reserved 0007 - 0920/16 
modern surgery. Therefore, identifying additional predictive and prognostic markers is an important step to improving current treatment approaches and extending survival.

The global, randomised, double-blind phase III AVAGAST (BO20904/AVF4200g) trial was conducted to evaluate the benefit of combining the vascular endothelial growth factor (VEGF) targeting antibody bevacizumab with cisplatin plus fluoropyrimidine $v s$ placebo plus chemotherapy as the first-line treatment for patients with advanced gastric cancer. Addition of bevacizumab significantly prolonged progression-free survival (PFS) compared with placebo (median, 6.7 vs 5.3 months; hazard ratio (HR), 0.80; $P=0.0037)$ and increased overall response rate $(46.0 \%$ vs $37.4 \%$; $P=0.0315)$. This was true both for Asian and non-Asian patients. However, the difference in overall survival (OS) - the primary study end point - did not reach statistical significance (12.1 vs 10.1 months; HR, 0.87; $P=0.1002$; Ohtsu et al, 2011). Yet, in subgroup analyses, a survival benefit from bevacizumab was observed in patients enrolled in North and Latin America (HR 0.63; 95\% CI $0.43-0.94)$, whereas patients enrolled in Asia had no benefit (90\% from Japan and Korea; HR 0.97; 95\% CI 0.75-1.25) and European patients showed intermediate-risk reduction (HR 0.85; 95\% CI $0.63-1.14$ ). Similar observations were made for the chemotherapy only arm with a median OS of 12.1 months in Asian, 8.6 months in European and 6.8 months in Pan-American patients (Ohtsu et al, 2011). In part, a higher rate of later line chemotherapy exposure in Asian patients might have contributed to these findings. It has not yet been clearly established that biological mechanisms contribute to the outcome differences observed between Asian and non-Asian patients. Although comprehensive molecular characterisation of gastric cancer did not show any systematic differences in the distribution of four subtypes of gastric cancer between patients of East Asian and Western origin (Cancer Genome Atlas Research Network, 2014), gene expression signatures of tumour immunity distinguished Asian and non-Asian gastric adenocarcinomas (Lin et al, 2015).

The value of antiangiogenic therapy for patients with previously treated advanced gastric or gastro-oesophageal junction adenocarcinoma has recently been demonstrated in the phase III REGARD trial comparing the VEGF-receptor-2 antibody ramucirumab with placebo in second-line treatment. Median OS was increased from 3.8 to 5.2 months in the ramucirumab arm compared with the placebo group; HR 0.776; 95\% CI 0.603-0.998; $P=0.047$. A similar survival benefit was observed when ramucirumab was combined with chemotherapy (Wilke et al, 2014). Despite intense efforts, however, predictive biomarkers indicating the efficacy of antiangiogenic treatment have not yet been developed and novel prognostic biomarkers are urgently needed (Murukesh et al, 2010; Hegde et al, 2013).

The Tie2 ligand Angiopoietin-2 (Ang2) mediates endothelial cell (EC) responsiveness to tumour-derived cytokines and has recently emerged as a promising target for second-generation antiangiogenic drug development that can be combined with established anti-VEGF/VEGFR therapies (Hashizume et al, 2010; Koh et al, 2010; Gerald et al, 2013; Srivastava et al, 2014). One of the earliest responses of activated ECs is to secrete Ang-2 to facilitate blood vessel destabilisation and induce angiogenesis (Gerald et al, 2013). The activity of Ang-2 as an opponent of VEGF inhibition has recently been investigated in preclinical tumour models. Specifically, upregulation of Ang-2 during anti-VEGF treatment was identified as a mechanism of acquired resistance (Daly et al, 2013; Rigamonti et al, 2014). In addition, Ang-2 has a central role in the vascular inflammatory response by recruiting bone marrow-derived myeloid cells (Scholz et al, 2011) that promote VEGF-independent tumour angiogenesis (Ferrara, 2010). More importantly, there is a growing body of evidence indicating that Ang-2 is centrally involved in the formation of tumour metastasis (Imanishi et al, 2007; Koh et al, 2010; Mazzieri et al,
2011; Schulz et al, 2011; Albini and Noonan, 2012; Holopainen et al, 2012; Im et al, 2013; Rigamonti and De Palma, 2013; Srivastava et al, 2014). Ang-2 not only controls the recruitment of tumour-promoting metastasis-associated macrophages but also affects the angiogenic response to myeloid-derived proangiogenic cytokines, such as Bv8 (Srivastava et al, 2014), which results in anti-VEGF refractoriness. Ang-2 thereby contributes to tumour progression by linking the metastatic inflammasome and the angiogenic programme.

On this basis, Ang-2 represents a promising biomarker in the context of VEGF-directed antiangiogenic cancer treatment. Plasma Ang-2 levels are elevated in cancer patients and are associated with a worse prognosis in a number of malignancies (Park et al, 2007; Helfrich et al, 2009; Goede et al, 2010; Maffei et al, 2010; Llovet et al, 2012). With respect to gastric cancer, preoperative Ang-2 levels correlated with lymph node status in patients with early gastric cancer (Jo et al, 2009).

Here we report on the value of Ang-2 as a biomarker in gastric cancer patients enrolled in the AVAGAST trial.

\section{MATERIALS AND METHODS}

Study design. The study design of the AVAGAST trial (NCT00548548) has been described previously. In brief, patients with untreated, histologically confirmed, unresectable, locally advanced or metastatic adenocarcinoma of the stomach or gastro-esophageal junction were assigned to bevacizumab $(n=387)$ or placebo $(n=387)$ in combination with cisplatin for six cycles plus capecitabine until disease progression or intolerable adverse effects occurred. In patients unable to take oral medications, fluorouracil was substituted for capecitabine. The protocol was approved at each participating site by an independent ethics committee or institutional review board. The trial was carried out in accordance with the declaration of Helsinki. All patients provided written informed consent before study entry.

Sample collection. The biomarker analysis was predefined in the study protocol. Baseline blood and tumour tissue (primary or recurrent) samples were collected from all randomly assigned patients. Blood samples ( $5 \mathrm{ml}$ collected in EDTA) for plasma isolation were taken between randomisation and start of treatment. Samples were analysed using a commercially available ELISA Kit (Quantikine; R\&D Systems GmbH, Wiesbaden, Germany) according to the instructions of the manufacturer. For the detection of VEGF-A, plasma samples were analysed at Roche Diagnostics (Penzberg, Germany) using IMPACT technology as previously described (Van Cutsem et al, 2012), which preferentially detects short VEGF isoforms.

Statistical analysis. The cutoff date for the primary efficacy analysis was 30 November 2009, when the predefined limit of 509 deaths was reached. Correlations between biomarkers and OS, defined as time between randomisation and death irrespective of cause, and PFS, defined as time between randomisation and first documented disease progression or death, was assessed. The median biomarker value at baseline was used to dichotomise patients into low or high biomarker groups. Time-to-event end points were analysed using Kaplan-Meier methods. The prognostic and predictive value of the biomarker was assessed using Cox proportional hazards models, including treatment group, biomarker group and interaction between treatment and biomarker as covariates in the model. Additional models that included stratification factors (i.e., geographic region, route of fluoropyrimidine treatment, disease status) as covariates were also evaluated. Logistic regression analysis was performed to investigate the correlation between liver metastasis and baseline Ang-2 levels and the odds ratio relating the presence of liver metastasis per 


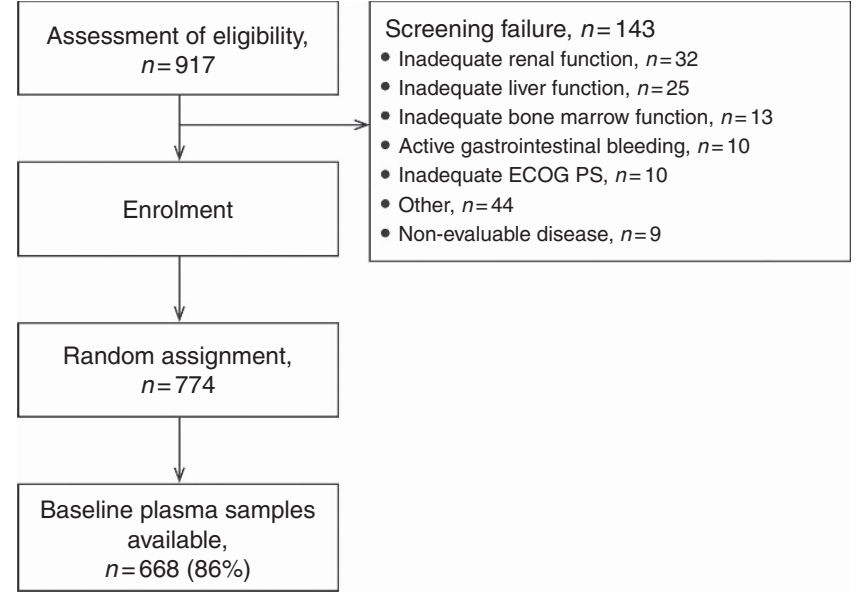

Figure 1. CONSORT diagram. ECOG = Eastern Cooperative Oncology Group; $\mathrm{Gl}=$ gastro-intestinal; PS = performance status.

$1000 \mathrm{pg} \mathrm{ml}^{-1}$ increase in baseline Ang-2 was calculated. Chi-square test was used to compare differences in the occurrence of liver metastasis during treatment for patients with high or low levels of the biomarker at baseline. All biomarker analyses were performed according to the REMARK criteria (McShane et al, 2005); for CONSORT diagram, see Figure 1.

\section{RESULTS}

Patients. From September 2007 to December 2008, 774 patients with advanced gastric cancer were enrolled in the AVAGST trial (Figure 1). Baseline plasma samples were available from 668 patients $(86 \%)$. Patient characteristics of the biomarker populations were similar to those of the overall study population (data not shown).

Ang-2 biomarker levels at baseline. Demographic variables (age und sex) of the Ang-2 biomarker populations (high vs low Ang-2) were well balanced. There was a weak correlation between prior (neo)-adjuvant or adjuvant therapy and low Ang-2 levels at baseline $(P=0.0405)$. Furthermore, there was a trend towards a decreased frequency of diffuse gastric cancer in the high Ang-2 cohort (44\% vs 52\%; $P=0.0528)$. On the other hand, Ang-2-high patients presented with a significantly higher frequency of liver metastasis at baseline $(42 \%$ vs $24 \% ; P>0.0001)$. In addition, the frequency of patients with $\geqslant 2$ metastatic sites $(69 \%$ vs $60 \%$; $P=0.02)$ and the frequency of bone lesions ( $7 \% v s 2 \% ; P=0.0016)$ was higher in the high Ang-2 cohort compared with the low Ang-2 cohort (Table 1). Because of the relation of Ang- 2 with obesity and the metabolic syndrome (Silha et al, 2005), we studied the association of plasma Ang-2 with body mass index (BMI) at baseline. Indeed, patients with a BMI $>25 \mathrm{~kg} \mathrm{~m}^{-2}$ had higher Ang2 levels than those with a BMI between 18.5 and $25 \mathrm{~kg} \mathrm{~m}^{-2}(2913.0$ vs $2393.0 \mathrm{pg} \mathrm{ml}^{-1}$ ). Interestingly, underweight/cachectic patients $\left(n=36 ; \mathrm{BMI}<18.5 \mathrm{~kg} \mathrm{~m}^{-2}\right)$ showed intermediate baseline plasma Ang-2 levels of $2643.0 \mathrm{pg} \mathrm{ml}^{-1}$ (Table 1).

Finally, baseline plasma Ang-2 levels were significantly higher in patients enrolled from non-Asian regions than in patients from the Asia-Pacific region (median Ang-2 2143 vs $3193 \mathrm{pg} \mathrm{ml}^{-1}$, $P<0.0001$; Mann-Whitney $U$-test).

Ang-2 prognostic biomarker evaluation. Median OS in the entire population (Figure 2) was longer in patients with low compared with high Ang-2 levels (13.7 months vs 10.0 months, HR 0.77; 95\% CI, 0.64 to $0.93 ; \quad P=0.0055)$, and Ang-2 levels retained independent prognostic value in a multivariate analysis, along with clinical characteristics (ECOG performance status, prior gastrectomy, liver metastasis and type of gastric cancer), HR 1.23; 95\% CI 1.01-1.49; $P=0.0385$ (Table 2). However, no correlation between baseline Ang-2 and PFS (Figure 2) was found in both univariate and multivariate analyses; HR 1.07; 95\% CI 0.90-1.27; $P=0.4566$. Additionally, separate analyses were carried out in the placebo arm and the bevacizumab arm, respectively, regarding PFS and OS according to Ang-2 biomarker levels high vs low. Low Ang-2 levels were associated with prolonged OS in both treatment armes analysed separately. Detailed data are given in Supplementary Table S1.

Ang-2 predictive biomarker evaluation. Biomarker analysis was performed for the entire available study cohort $(n=668)$. Ang-2 baseline levels were not predictive of clinical outcome in response to bevacizumab. The HR for PFS in the low Ang-2 group was 0.79; 95\% CI $0.62-0.99$ vs $0.8295 \%$ CI $0.65-1.03$ in the high Ang-2 group. The HR for OS in the low Ang-2 group was 0.80; 95\% CI $0.62-1.05$ vs 0.87 ; $95 \%$ CI $0.67-0.1 .13$ in the high Ang-2 group with an interaction $P$-value of 0.74 . In multiple Cox regression models, Ang-2 levels were not predictive of benefit from bevacizumab with respect to PFS or OS. In addition, subgroup analysis for each ethnic group (Asians vs non-Asians) using the Ang-2 medians for dichotomisation failed to demonstrate a predictive role for the response to bevacizumab (Supplementary Figure S1). Forest plots of HR for PFS and OS were analysed for subgroups with VEGF and Ang-2, respectively, either being high/high, high/low, low/high or low/low. These analyses demonstrated that VEGF was the predominant marker in predicting the response to bevacizumab in non-Asian patients and Ang-2 did not contribute significantly in this respect (Figure 3).

Ang-2 and liver metastasis. Baseline plasma Ang-2 levels were higher in patients with liver metastasis than in patients without liver metastasis $\left(3175.5 \mathrm{pg} \mathrm{ml}^{-1}\right.$ compared with $2374 \mathrm{pg} \mathrm{ml}^{-1}$, $P<0.0001$; Table 1). The frequency of liver metastasis was higher in non-Asian than in Asian patients (39\% vs 28\%, Chi-Square; $P=0.003)$ and correlated with baseline Ang-2 levels. In non-Asian patients, the frequency of liver metastasis in the high $v s$ low Ang-2 group was $45 \%$ and $27 \%$, respectively. In Asian patients, the frequency of liver metastasis at baseline in the high $v$ s low Ang-2 group was $37 \%$ and $23 \%$, respectively. Logistic regression analysis confirmed that Ang-2 levels were strongly correlated with the frequency of liver metastasis at any time (Figure 4). The odds ratio per $1000 \mathrm{pg} \mathrm{ml}^{-1}$ increase in baseline plasma Ang-2 was 1.19; $95 \%$ CI 1.10-1.29; $P<0.0001$ (non-Asian) and 1.37; 95\% CI 1.13-1.64; $P=0.0010$ (Asian).

A total of 16 of the 445 patients without liver metastasis at baseline (3.6\%) developed liver metastasis at progression and 44 of the 222 patients $(19.8 \%)$ who initially presented with liver metastasis developed new metastatic lesions in the liver during treatment.

Ang-2 levels at progression. Given that Ang-2 is biologically involved in tumour progression and metastasis, we examined plasma samples at progression in 379 of the 668 patients $(56.7 \%)$. Interestingly, in the entire cohort, there was no change in median Ang-2 levels (2567 vs $2521.0 \mathrm{pg} \mathrm{ml}^{-1}$, NS) upon progression. In fact, Ang-2 levels $\left(2217.0 \mathrm{pg} \mathrm{ml}^{-1} ; n=183\right)$ at progression were lower in bevacizumab-treated patients compared with patient receiving chemotherapy only $\left(2891.0 \mathrm{pg} \mathrm{ml}^{-1} ; n=196\right)$. In patients $(n=16)$ who were free of liver metastasis at baseline and who developed liver metastasis at progression, Ang-2 levels increased from 2476 to $2899 \mathrm{pg} \mathrm{ml}^{-1}$ and an even distribution regarding ethnicity as well as treatment arm was found (Supplementary Figure S2). In the presence of liver metastasis, bevacizumab treatment was associated with a marked decrease in 
Table 1. Clinical characteristics by baseline Ang-2 biomarker

\begin{tabular}{|c|c|c|c|c|c|}
\hline & $\begin{array}{c}\text { Ang-2 }(n=668) \text { median } \\
\text { biomarker level }\end{array}$ & $P$-value & Ang-2 low level & Ang-2 high level & $P$-value \\
\hline \multicolumn{6}{|c|}{ ECOG PS } \\
\hline $\begin{array}{l}\geqslant 1 \\
0\end{array}$ & $\begin{array}{l}2707.0 \\
2478.0\end{array}$ & 0.0036 & $\begin{array}{l}168(50 \%) \\
166(50 \%)\end{array}$ & $\begin{array}{l}191(57 \%) \\
143(43 \%)\end{array}$ & 0.0877 \\
\hline \multicolumn{6}{|c|}{ Prior gastrectomy } \\
\hline $\begin{array}{l}\text { No } \\
\text { Yes }\end{array}$ & $\begin{array}{l}2568.0 \\
2564.0\end{array}$ & 0.6129 & $\begin{array}{r}240(72 \%) \\
94(28 \%)\end{array}$ & $\begin{array}{r}241(72 \%) \\
93(28 \%)\end{array}$ & 1.0000 \\
\hline $\begin{array}{l}\text { No } \\
\text { Yes }\end{array}$ & $\begin{array}{l}2607.0 \\
2125.0\end{array}$ & 0.0133 & $\begin{array}{r}301(90 \%) \\
33(10 \%)\end{array}$ & $\begin{array}{c}316 \text { (95\%) } \\
18 \text { (5\%) }\end{array}$ & 0.0405 \\
\hline \multicolumn{6}{|c|}{ Age category, years } \\
\hline $\begin{array}{l}40-65 \\
<40 \\
\geqslant 65\end{array}$ & $\begin{array}{l}2515.0 \\
2485.5 \\
2608.0\end{array}$ & 0.1379 & & & \\
\hline \multicolumn{6}{|l|}{ Sex } \\
\hline $\begin{array}{l}\text { Female } \\
\text { Male }\end{array}$ & $\begin{array}{l}2638.5 \\
2503.0\end{array}$ & 0.5450 & $\begin{array}{l}102(31 \%) \\
232(69 \%)\end{array}$ & $\begin{array}{l}114(34 \%) \\
220(66 \%)\end{array}$ & 0.3629 \\
\hline \multicolumn{6}{|c|}{ Liver metastasis } \\
\hline $\begin{array}{l}\text { No } \\
\text { Yes }\end{array}$ & $\begin{array}{l}2374.0 \\
3175.5\end{array}$ & $<0.0001$ & $\begin{array}{r}253(76 \%) \\
81(24 \%)\end{array}$ & $\begin{array}{l}192(57 \%) \\
141(42 \%)\end{array}$ & $<0.0001$ \\
\hline \multicolumn{6}{|c|}{ Number of metastatic sites at baseline } \\
\hline $\begin{array}{l}\leqslant 1 \\
\geqslant 2\end{array}$ & $\begin{array}{l}2391.0 \\
2707.0 \\
\end{array}$ & 0.0014 & $\begin{array}{l}133(40 \%) \\
201(60 \%)\end{array}$ & $\begin{array}{l}104(31 \%) \\
230(69 \%)\end{array}$ & 0.0235 \\
\hline \multicolumn{6}{|c|}{ Bone metastasis at baseline } \\
\hline $\begin{array}{l}\text { No } \\
\text { Yes }\end{array}$ & $\begin{array}{l}2503.0 \\
3532.0\end{array}$ & 0.0004 & $\begin{array}{l}327 \text { (98\%) } \\
\quad 7 \text { (2\%) }\end{array}$ & $\begin{array}{c}309 \text { (93\%) } \\
24 \text { (7\%) }\end{array}$ & 0.0016 \\
\hline
\end{tabular}

plasma Ang-2 levels at progression while in the chemotherapytreated group there was a trend towards increased plasma Ang-2 levels at progression (Supplementary Table S2).

In summary, we found that (i) Ang-2 levels at baseline are higher in non-Asian compared with Asian gastric cancer patients; (ii) baseline plasma Ang-2 does not predict response to bevacizumab treatment; (iii) baseline plasma Ang-2 represents a novel prognostic biomarker in gastric cancer; and (iv) baseline Ang-2 levels strongly correlate with the frequency of liver metastasis across both ethnic groups.

These findings highlight differences between ethnic groups in gastric cancer patients related to tumour angiogenesis. To the best of our knowledge, these are the first data derived from a large clinical trial correlating plasma Ang-2 levels with metastasis in gastric cancer.

\section{DISCUSSION}

Within the biomarker programme of the AVAGAST trial, we studied the role of Ang-2 as a biomarker in advanced gastric cancer patients.

There is accumulating evidence that Asian and non-Asian gastric cancer patients differ in the course and prognosis of the disease (Gill et al, 2003; Kim et al, 2010). In our analyses, baseline Ang-2 levels were significantly lower in Asian compared with non-Asian gastric cancer patients, and similar differences were recently reported regarding baseline VEGF levels (Van Cutsem et al, 2012). Of note, even in healthy individuals Ang-2 levels are lower in Asians vs non-Asians (Cho et al, 2011). From this background, it can be speculated that genetic and/or environmental factors exist, which might be related to differences in angiogenic response between non-Asian and Asian gastric cancer patients that might influence clinical outcome. Data on biological variables related to outcome differences, however, are controversial: comprehensive molecular characterisation of gastric cancer did not show any systematic differences in distribution of subtypes between patients of East Asian and Western origin (Cancer Genome Atlas Research Network, 2014). In contrast, gene expression signatures of tumour immunity distinguished Asian and non-Asian gastric adenocarcinomas (Lin et al, 2015). Our findings have to be validated in additional cohorts.

Despite the fact that extensive efforts have been made, no biomarker has been identified, predicting the efficacy of antiangiogenic drug treatment. In the AVAGAST trial, baseline VEGFA levels have been proposed to be predictive for the benefit to bevacizumab treatment specifically in the non-Asian study population (Van Cutsem et al, 2012). Despite the fact that 
A

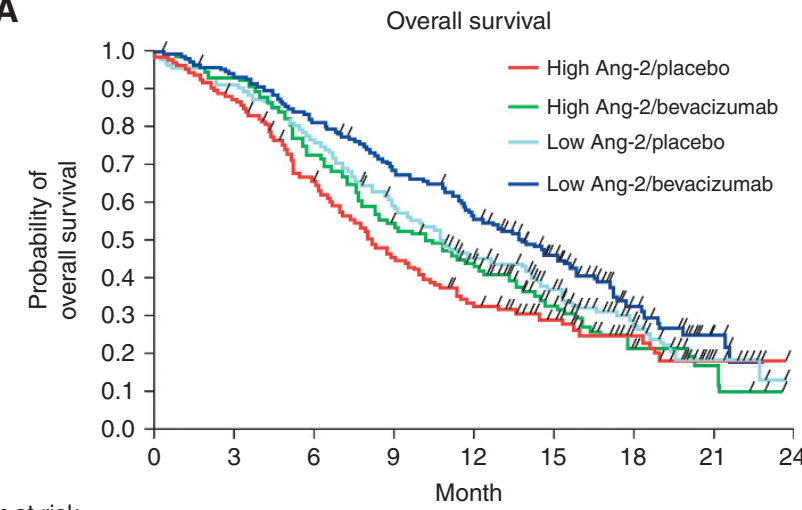

$n$ at risk

$\begin{array}{llllllllll}\text { High Ang-2 } & 334 & 298 & 228 & 170 & 126 & 73 & 38 & 14 & 0\end{array}$

$\begin{array}{llllllllll}\text { Low Ang-2 } & 334 & 311 & 269 & 219 & 170 & 113 & 60 & 19 & 0\end{array}$

C

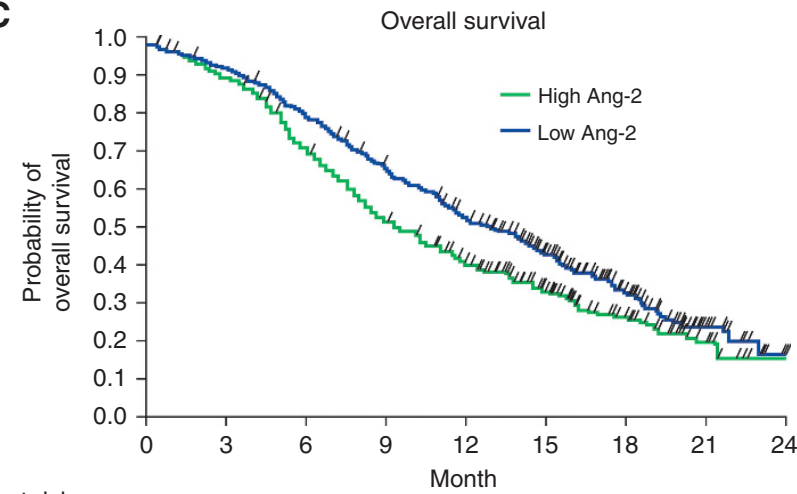

$n$ at risk

$\begin{array}{llllllllll}\text { High Ang-2 } & 334 & 298 & 228 & 170 & 126 & 73 & 38 & 14 & 0\end{array}$

$\begin{array}{llllllllll}\text { Low Ang-2 } & 334 & 311 & 269 & 219 & 170 & 113 & 60 & 19 & 0\end{array}$
B

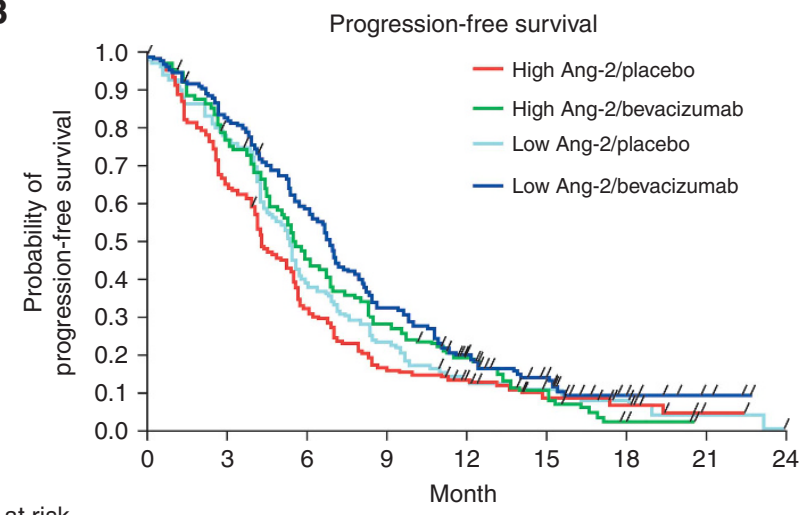

$n$ at risk

$\begin{array}{llllllllll}\text { High Ang-2 } & 334 & 241 & 137 & 83 & 36 & 26 & 8 & 1 & 0\end{array}$

$\begin{array}{llllllllll}\text { Low Ang-2 } & 334 & 271 & 168 & 102 & 61 & 39 & 16 & 5 & 0\end{array}$

D

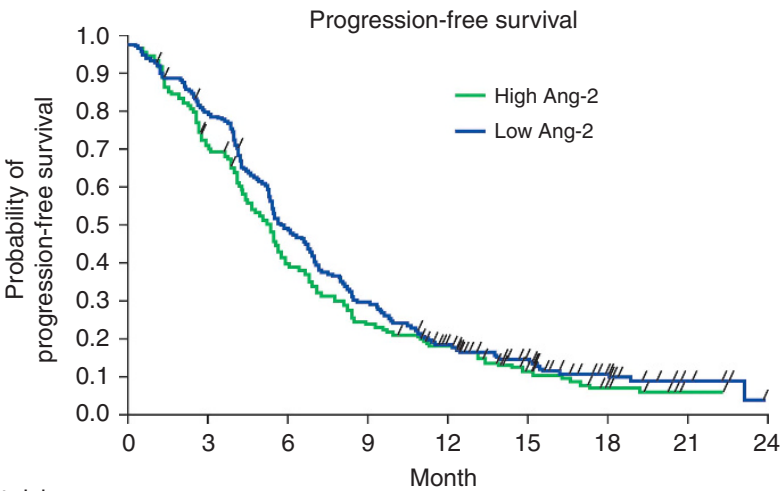

$n$ at risk

$\begin{array}{llllllllll}\text { High Ang-2 } & 334 & 241 & 137 & 83 & 36 & 26 & 8 & 1 & 0\end{array}$

$\begin{array}{llllllllll}\text { Low Ang-2 } & 334 & 271 & 168 & 102 & 61 & 39 & 16 & 5 & 0\end{array}$

Figure 2. Overall survival and progression-free survival according to baseline Ang-2 levels. (A) Kaplan-Meier estimates of overall survival according to treatment arm and biomarker level. (B) Kaplan-Meier estimates of progression-free survival according to treatment arm and biomarker level (i.e., baseline plasma Ang-2 levels dichotomised by median value). (C) Kaplan-Meier curves of overall survival according to biomarker and (D) Kaplan-Meier curves of progression-free survival according to biomarker including both treatment arms (entire biomarker population).

Table 2. Multivariate analyses of all-patient cohorts to identify factors independently prognostic for OS in patients with advanced or metastatic gastric cancer

\begin{tabular}{|c|c|c|c|}
\hline Effect/covariate included in the model & Hazard ratio & $\begin{array}{l}95 \% \text { confidence interval } \\
\text { for hazard ratio }\end{array}$ & $P$-value \\
\hline Biomarker level (median cutoff) & 1.23 & $1.01-1.49$ & 0.0385 \\
\hline ECOG performance status ( $\geqslant 1$ vs 0$)$ & 1.70 & $1.39-2.07$ & $<0.0001$ \\
\hline Prior gastrectomy (yes vs no) & 0.60 & $0.47-0.77$ & $<0.0001$ \\
\hline Prior adjuvant/neoadjuvant chemotherapy (yes vs no) & 1.07 & $0.07-1.63$ & 0.7582 \\
\hline Age at randomisation (years) & 1.00 & $0.99-1.00$ & 0.2946 \\
\hline Sex (male vs female) & 1.11 & $0.90-1.37$ & 0.3240 \\
\hline Liver metastasis (yes vs no) & 1.31 & $1.04-1.65$ & 0.0198 \\
\hline Number of metastatic sites at baseline ( $\geqslant 2$ vs $\leqslant 1$ ) & 1.13 & $0.91-1.41$ & 0.2613 \\
\hline Bone metastasis at baseline (yes vs no) & 1.42 & $0.94-2.19$ & 0.0977 \\
\hline Type of gastric cancer (intestinal vs mixed) & 0.72 & $0.53-0.96$ & 0.0240 \\
\hline Type of gastric cancer (diffuse vs mixed) & 1.01 & $0.76-1.34$ & 0.9539 \\
\hline
\end{tabular}

preclinical data indicate an interaction between Ang-2 and VEGF that potentially influences the efficacy of VEGF-targeting drugs (Ferrara, 2010; Kim and Koh, 2011; Rigamonti et al, 2014), baseline Ang-2 levels were not predictive for OS or PFS in response to bevacizumab in our study. Moreover, combined VEGF/Ang-2 biomarker evaluation did not further improve the predictive value already demonstrated for VEGF (Van Cutsem et al, 2012).
Ang-2 was identified as a novel prognostic biomarker of survival in advanced gastric cancer as demonstrated by multivariate analysis. In line with our findings, baseline plasma or serum Ang-2 has previously been shown to be a prognostic biomarker of survival in other solid tumour entities, such as colorectal cancer, hepatocellular carcinoma, non-small cell lung cancer and melanoma (Park et al, 2007; Helfrich et al, 2009; Goede et al, 2010; Volkova et al, 2011; Llovet et al, 2012). 
A

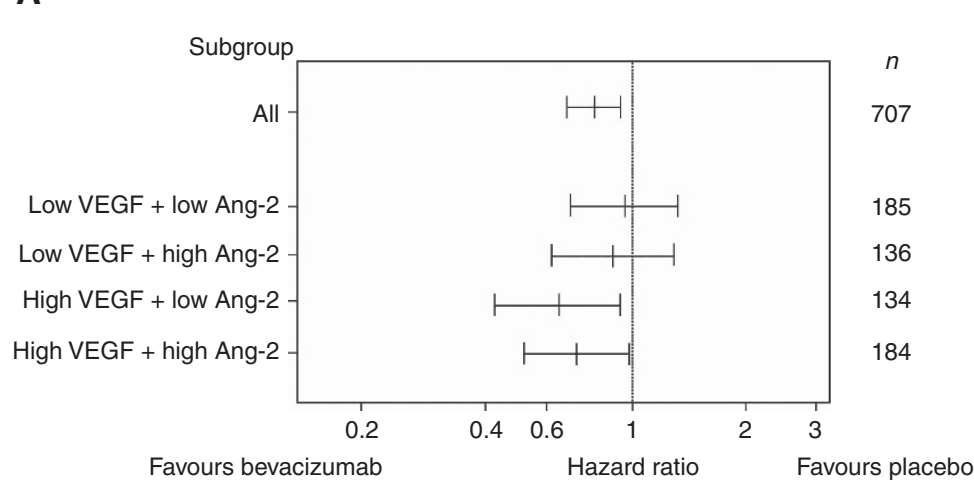

$\begin{array}{ccc}\begin{array}{c}\text { Lower } \\ \text { confidence } \\ \text { limit }\end{array} & \text { Estimate } & \begin{array}{c}\text { Upper } \\ \text { confidence } \\ \text { limit }\end{array} \\ 0.69 & 0.80 & 0.94 \\ 0.70 & 0.96 & 1.31 \\ 0.62 & 0.90 & 1.28 \\ 0.45 & 0.65 & 0.94 \\ 0.53 & 0.72 & 0.99\end{array}$

B

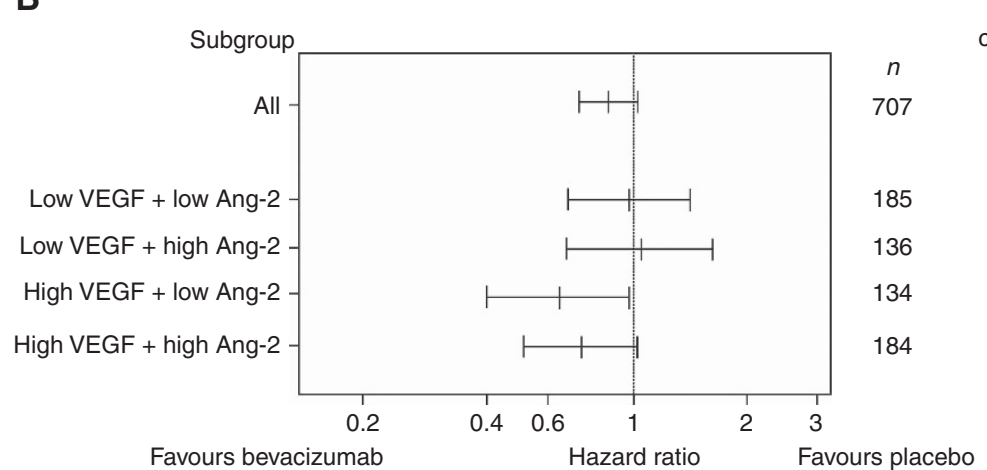

$\begin{array}{ccc}\begin{array}{c}\text { Lower } \\ \text { confidence } \\ \text { limit }\end{array} & \begin{array}{c}\text { Estimate } \\ \text { Upper } \\ 0.72\end{array} & \begin{array}{c}\text { confidence } \\ \text { limit }\end{array} \\ 0.86 & 1.03 \\ 0.68 & 0.98 & 1.42 \\ 0.68 & 1.05 & 1.61 \\ 0.42 & 0.64 & 0.97 \\ 0.52 & 0.74 & 1.03\end{array}$

Figure 3. Combined VEGF/Ang-2 biomarker analysis. Forest plots of hazard ratios (bevacizumab plus chemotherapy vs placebo plus chemotherapy) for (A) progression-free survival by biomarker and (B) overall survival by biomarker (high VEGF/high Ang-2; high VEGF/low Ang-2; low VEGF/high Ang-2 and low VEGF/low Ang-2).

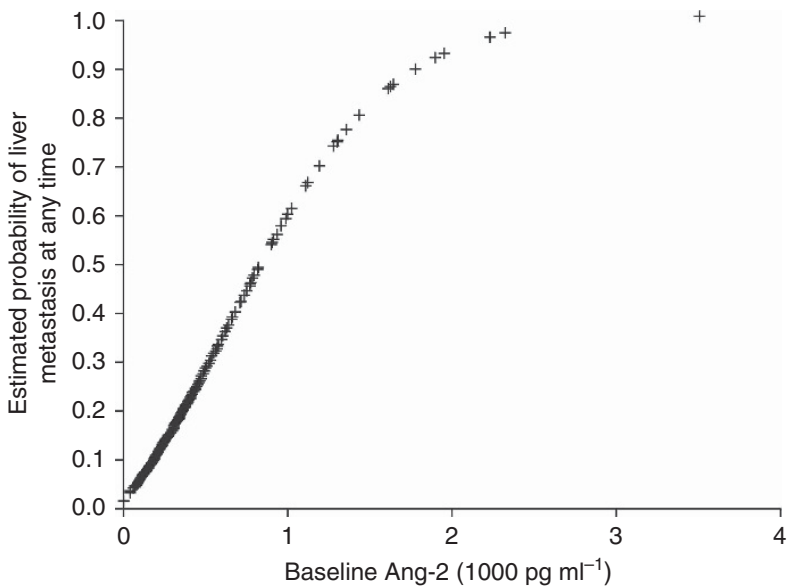

Figure 4. Logistic regression analysis: Baseline Ang-2 levels and frequency of liver metastasis at baseline.

In our study, the frequency of liver metastasis was strongly correlated with baseline Ang-2 levels across ethnic groups (Figure 4). It is tempting to speculate that this association might contribute to the reduced OS in gastric cancer patients with elevated Ang-2 levels. Interestingly, the presence of bone metastasis was also correlated with high pretherapeutic Ang-2 levels $(P=0.0016)$; however, in view of the overall low number of cases with bone metastasis, no further statistical analysis was performed (Table 1). Recently, a number of preclinical studies in patients with pancreatic ductal adenocarcinoma (Schulz et al, 2011), breast cancer (Sfiligoi et al, 2003) and early gastric cancer (Jo et al, 2009) have demonstrated that Ang-2 levels were correlated with lymph node metastasis, and preclinical studies indicate that Ang-2 is centrally involved in the formation of tumour metastasis
(Imanishi et al, 2007; Koh et al, 2010; Mazzieri et al, 2011; Minami et al, 2013; Schulz et al, 2011; Albini and Noonan, 2012; Holopainen et al, 2012; Im et al, 2013; Rigamonti and De Palma, 2013; Srivastava et al, 2014). Although Ang-2 plasma levels in our study may reflect the extent of disease, the finding that plasma Ang-2 levels did not further increase at progression in the entire cohort at least points to possible site-specific differences with respect to liver metastasis. Although we cannot validate this hypothesis owing to the lack of availability of tumour tissue from primary tumour $v s$ metastatic sites in our cohort, recent data from colorectal cancer patients clearly demonstrated increased Ang-2 protein levels in liver metastases compared with respective primary tumours and lung metastases (Kahlert et al, 2014).

Another question that cannot be addressed by the data presented here is the origin of Ang-2 expression that results in the plasma levels observed in gastric cancer patients. Ang-2 is preferentialy expressed in ECs and subsequently stored in the Weibel Pallade bodies. In line with this finding, a number of studies has demonstrated increased Ang-2 expression within the tumour stroma (Goede et al, 2010), while tumour cell-derived expression was limited to distinct tumour entities (Koga et al, 2001; Sfiligoi et al, 2003; Lee et al, 2006). In this respect, very recently, mechanisms have been identified that lead to an upregulation of Ang-2 expression in gastric cancer cells (Chen et al, 2015). Additionally, induction of Ang-2 from non-neoplastic vasculature related to vascular inflammatory response (Fiedler et al, 2006; Kim and Koh, 2011) might represent another source of plasma Ang-2. As an example, circulating Ang-2 levels are increased in overweight and obese individuals (Silha et al, 2005). In line with this, we found higher Ang-2 levels in patients with a BMI $>25 \mathrm{~kg} \mathrm{~m}^{-2}$ compared with those with a BMI between 18.5 and $25 \mathrm{~kg} \mathrm{~m}^{-2}$ (2913.0 vs $2393.0 \mathrm{pg} \mathrm{ml}^{-1}$ ). In contrast, underweight/cachectic patients $\left(n=36 ; \mathrm{BMI}<18.5 \mathrm{~kg} \mathrm{~m}^{-2}\right)$ showed intermediate baseline plasma Ang-2 levels of $2643.0 \mathrm{pg} \mathrm{ml}^{-1}$, and it can be speculated that an 
increased inflammatory response (Tsoli and Robertson, 2013) in cancer cachexia might contribute to this finding.

Finally, an analysis including the entire cohort revealed that Ang-2 levels at metastatic progression were unchanged. In the bevacizumab-treated group, however, Ang-2 levels were decreased at progression, compared with the chemotherapy only group (2217.0 vs $\left.2891.0 \mathrm{pg} \mathrm{ml}^{-1}\right)$. This finding was specifically true for patients with liver metastasis at baseline (see Supplementary Table S2). Interestingly, data from a mouse RIP1-Tag2 model of pancreatic neuroendocrine tumours correlated upregulation of Ang-2 with resistance to anti-VEGF treatment. On the other hand, in a murine model of ovarian cancer, VEGF induced the expression of Ang-2 (Zhang et al, 2003). Thus inhibition of VEGF might indeed be related to a decrease in Ang-2 production.

Recently, trebananib demonstrated improved PFS in a phase III study (Monk et al, 2014) in women with recurrent ovarian cancer but later on failed to improve OS (Sheridan, 2015). The specific mechanism of trebananib targeting both Ang-1 and Ang-2 has been discussed as a possible reason for these negative results, given the role of Ang-1 in maintaining normal vasculature and its inhibitory effect on metastasis. In addition, the fact that Ang-2 is most important during early stages of tumour progression (Helfrich et al, 2009) may have had a role. Other drugs are currently in late-stage clinical development targeting Ang-2 alone or in combination with VEGF (Brown et al, 2010; Huang et al, 2011; Karlan et al, 2012; Kienast et al, 2013). The data presented here should encourage the initiation of clinical trials testing such compounds in the adjuvant and palliative setting in gastric cancer patients. Both the central role of Ang-2 in tumour angiogenesis, which represents an important and well-established target in advanced gastric cancer treatment, and recent findings linking the pro-tumorigenic activity of dopamine and cAMP-regulated phosphoprotein, Mr 32000 (DARPP-32), which is overexpressed in gastric cancer, with STAT3-mediated upregulation of Ang-2 expression in gastric cancer tumour cells (Chen et al, 2015) point towards a role of Ang-2 as a drug target in gastric cancer.

In summary, marked differences in baseline plasma Ang-2 levels exist between Asian and non-Asian gastric cancer patients. Ang-2 is not a predictive biomarker for becacizumab efficiency in gastric cancer but has a role as an independent prognostic biomarker for survival and is strongly correlated with liver metastasis. Based on this, the biomarker might prove valuable for the stratification of patients with advanced gastric cancer before randomisation in clinical trials. Ang-2 represents a promising drug target in gastric cancer.

\section{ACKNOWLEDGEMENTS}

We thank Professor Dr F Lordick and Dr D Hasenclever for most helpful discussions.

\section{CONFLICT OF INTEREST}

Genentech has provided financial support to the University of Cologne (UT Hacker) to carry out this project. There are no other potential conflicts of interest.

\section{REFERENCES}

Albini A, Noonan DM (2012) Angiopoietin2 and Tie2: tied to lymphangiogenesis and lung metastasis. New perspectives in antimetastatic antiangiogenic therapy. J Natl Cancer Inst 104(6): 429-431.

Bollschweiler E, Boettcher K, Hoelscher AH, Sasako M, Kinoshita T, Maruyama K, Siewert JR (1993) Is the prognosis for Japanese and German patients with gastric cancer really different? Cancer 71(10): 2918-2925.
Brenner H, Rothenbacher D, Arndt V (2009) Epidemiology of stomach cancer. Methods Mol Biol 472: 467-477.

Brown JL, Cao ZA, Pinzon-Ortiz M, Kendrew J, Reimer C, Wen S, Zhou JQ, Tabrizi M, Emery S, McDermott B, Pablo L, McCoon P, Bedian V, Blakey DC (2010) A human monoclonal anti-ANG2 antibody leads to broad antitumor activity in combination with VEGF inhibitors and chemotherapy agents in preclinical models. Mol Cancer Ther 9(1): 145-156.

Cancer Genome Atlas Research Network (2014) Comprehensive molecular characterization of gastric adenocarcinoma. Nature 513(7517): 202-209.

Chen Z, Zhu S, Hong J, Soutto M, Peng D, Belkhiri A, Xu Z, El-Rifai W (2015) Gastric tumour-derived ANGPT2 regulation by DARPP-32 promotes angiogenesis. Gut 0: 1-10.

Cho YJ, Ma JE, Yun EY, Kim YE, Kim HC, Lee JD, Hwang YS, Jeong YY (2011) Serum angiopoietin-2 levels are elevated during acute exacerbations of COPD. Respirology 16(2): 284-290.

Daly C, Eichten A, Castanaro C, Pasnikowski E, Adler A, Lalani AS, Papadopoulos N, Kyle AH, Minchinton AI, Yancopoulos GD, Thurston G (2013) Angiopoietin-2 functions as a Tie2 agonist in tumor models, where it limits the effects of VEGF inhibition. Cancer Res 73(1): 108-118.

Ferrara N (2010) Role of myeloid cells in vascular endothelial growth factorindependent tumor angiogenesis. Curr Opin Hematol 17(3): 219-224.

Fiedler U, Reiss Y, Scharpfenecker M, Grunow V, Koidl S, Thurston G, Gale NW, Witzenrath M, Rosseau S, Suttorp N, Sobke A, Herrmann M, Preissner KT, Vajkoczy P, Augustin HG (2006) Angiopoietin-2 sensitizes endothelial cells to TNF-alpha and has a crucial role in the induction of inflammation. Nat Med 12(2): 235-239.

Gerald D, Chintharlapalli S, Augustin HG, Benjamin LE (2013) Angiopoietin2: an attractive target for improved antiangiogenic tumor therapy. Cancer Res 73(6): 1649-1657.

Gill S, Shah A, Le N, Cook EF, Yoshida EM (2003) Asian ethnicity-related differences in gastric cancer presentation and outcome among patients treated at a canadian cancer center. J Clin Oncol 21(11): 2070-2076.

Goede V, Coutelle O, Neuneier J, Reinacher-Schick A, Schnell R, Koslowsky TC, Weihrauch MR, Cremer B, Kashkar H, Odenthal M, Augustin HG, Schmiegel W, Hallek M, Hacker UT (2010) Identification of serum angiopoietin-2 as a biomarker for clinical outcome of colorectal cancer patients treated with bevacizumab-containing therapy. Br J Cancer 103(9): 1407-1414.

Hashizume H, Falcon BL, Kuroda T, Baluk P, Coxon A, Yu D, Bready JV, Oliner JD, McDonald DM (2010) Complementary actions of inhibitors of Angiopoietin-2 and VEGF on tumor angiogenesis and growth. Cancer Res 70(6): 2213-2223.

Hegde PS, Jubb AM, Chen D, Li NF, Meng YG, Bernaards C, Elliott R, Scherer SJ, Chen DS (2013) Predictive impact of circulating vascular endothelial growth factor in four phase III trials evaluating bevacizumab. Clin Cancer Res 19(4): 929-937.

Helfrich I, Edler L, Sucker A, Thomas M, Christian S, Schadendorf D, Augustin HG (2009) Angiopoietin-2 levels are associated with disease progression in metastatic malignant melanoma. Clin Cancer Res 15(4): 1384-1392.

Holopainen T, Saharinen P, D’Amico G, Lampinen A, Eklund L, Sormunen R, Anisimov A, Zarkada G, Lohela M, Helotera H, Tammela T, Benjamin LE, Yla-Herttuala S, Leow CC, Koh GY, Alitalo K (2012) Effects of angiopoietin-2-blocking antibody on endothelial cell-cell junctions and lung metastasis. J Natl Cancer Inst 104(6): 461-475.

Huang H, Lai JY, Do J, Liu D, Li L, Del Rosario J, Doppalapudi VR, Pirie-Shepherd S, Levin N, Bradshaw C, Woodnutt G, Lappe R, Bhat A (2011) Specifically targeting angiopoietin-2 inhibits angiogenesis, Tie2-expressing monocyte infiltration, and tumor growth. Clin Cancer Res 17(5): 1001-1011.

Im JH, Tapmeier T, Balathasan L, Gal A, Yameen S, Hill S, Smart S, Noterdaeme O, Kelly M, Brady M, Fu W, Kruse K, Bernhard EJ, Augustin HG, Muschel RJ (2013) G-CSF rescues tumor growth and neo-angiogenesis during liver metastasis under host angiopoietin-2 deficiency. Int J Cancer 132(2): 315-326.

Imanishi Y, Hu B, Jarzynka MJ, Guo P, Elishaev E, Bar-Joseph I, Cheng SY (2007) Angiopoietin-2 stimulates breast cancer metastasis through the alpha(5)beta(1) integrin-mediated pathway. Cancer Res 67(9): 4254-4263.

Jemal A, Bray F, Center MM, Ferlay J, Ward E, Forman D (2011) Global cancer statistics. CA Cancer J Clin 61(2): 69-90.

Jo MJ, Lee JH, Nam BH, Kook MC, Ryu KW, Choi IJ, Kim YW, Bae JM (2009) Preoperative serum angiopoietin-2 levels correlate with lymph node status in patients with early gastric cancer. Ann Surg Oncol 16(7): 2052-2057.

Kahlert C, Pecqueux M, Halama N, Dienemann H, Muley T, Pfannschmidt J, Lasitschka F, Klupp F, Schmidt T, Rahbari N, Reissfelder C, Kunz C, 
Benner A, Falk C, Weitz J, Koch M (2014) Tumour-site-dependent expression profile of angiogenic factors in tumour-associated stroma of primary colorectal cancer and metastases. Br J Cancer 110(2): 441-449.

Kamangar F, Dores GM, Anderson WF (2006) Patterns of cancer incidence, mortality, and prevalence across five continents: defining priorities to reduce cancer disparities in different geographic regions of the world. J Clin Oncol 24(14): 2137-2150.

Karlan BY, Oza AM, Richardson GE, Provencher DM, Hansen VL, Buck M, Chambers SK, Ghatage P, Pippitt Jr. CH, Brown 3rd JV, Covens A, Nagarkar RV, Davy M, Leath 3rd CA, Nguyen H, Stepan DE, Weinreich DM, Tassoudji M, Sun YN, Vergote IB (2012) Randomized, double-blind, placebo-controlled phase II study of AMG 386 combined with weekly paclitaxel in patients with recurrent ovarian cancer. J Clin Oncol 30(4): 362-371.

Kienast Y, Klein C, Scheuer W, Raemsch R, Lorenzon E, Bernicke D, Herting F, Yu S, The HH, Martarello L, Gassner C, Stubenrauch KG, Munro K, Augustin HG, Thomas M (2013) Ang-2-VEGF-A CrossMab, a novel bispecific human IgG1 antibody blocking VEGF-A and Ang-2 functions simultaneously, mediates potent antitumor, antiangiogenic, and antimetastatic efficacy. Clin Cancer Res 19(24): 6730-6740.

Kim H, Koh GY (2011) Ang2, the instigator of inflammation. Blood 118(18): $4767-4768$.

Kim J, Sun CL, Mailey B, Prendergast C, Artinyan A, Bhatia S, Pigazzi A, Ellenhorn JD (2010) Race and ethnicity correlate with survival in patients with gastric adenocarcinoma. Ann Oncol 21(1): 152-160.

Koga K, Todaka T, Morioka M, Hamada J, Kai Y, Yano S, Okamura A, Takakura N, Suda T, Ushio Y (2001) Expression of angiopoietin-2 in human glioma cells and its role for angiogenesis. Cancer Res 61(16): 6248-6254.

Koh YJ, Kim HZ, Hwang SI, Lee JE, Oh N, Jung K, Kim M, Kim KE, Kim H, Lim NK, Jeon CJ, Lee GM, Jeon BH, Nam DH, Sung HK, Nagy A, Yoo OJ, Koh GY (2010) Double antiangiogenic protein, DAAP, targeting VEGF-A and angiopoietins in tumor angiogenesis, metastasis, and vascular leakage. Cancer Cell 18(2): 171-184.

Lee OH, Fueyo J, Xu J, Yung WK, Lemoine MG, Lang FF, Bekele BN, Zhou X, Alonso MA, Aldape KD, Fuller GN, Gomez-Manzano C (2006) Sustained angiopoietin-2 expression disrupts vessel formation and inhibits glioma growth. Neoplasia 8(5): 419-428.

Lin SJ, Gagnon-Bartsch JA, Tan IB, Earle S, Ruff L, Pettinger K, Ylstra B, van Grieken N, Rha SY, Chung HC, Lee JS, Cheong JH, Noh SH, Aoyama T, Miyagi Y, Tsuburaya A, Yoshikawa T, Ajani JA, Boussioutas A, Yeoh KG, Yong WP, So J, Lee J, Kang WK, Kim S, Kameda Y, Arai T, Zur Hausen A, Speed TP, Grabsch HI, Tan P (2015) Signatures of tumour immunity distinguish Asian and non-Asian gastric adenocarcinomas. Gut 64: 1721-1731.

Llovet JM, Pena CE, Lathia CD, Shan M, Meinhardt G, Bruix J. Group SIS (2012) Plasma biomarkers as predictors of outcome in patients with advanced hepatocellular carcinoma. Clin Cancer Res 18(8): 2290-2300.

Maffei R, Martinelli S, Santachiara R, Rossi D, Guarnotta C, Sozzi E, Zucchetto A, Rigolin GM, Fiorcari S, Castelli I, Fontana M, Coluccio V, Leonardi G, Zucchini P, Tripodo C, Cuneo A, Gattei V, Del Poeta G, Forconi F, Gaidano G, Torelli G, Marasca R (2010) Angiopoietin-2 plasma dosage predicts time to first treatment and overall survival in chronic lymphocytic leukemia. Blood 116(4): 584-592.

Mazzieri R, Pucci F, Moi D, Zonari E, Ranghetti A, Berti A, Politi LS, Gentner B, Brown JL, Naldini L, De Palma M (2011) Targeting the ANG2/TIE2 axis inhibits tumor growth and metastasis by impairing angiogenesis and disabling rebounds of proangiogenic myeloid cells. Cancer Cell 19(4): 512-526.

McShane LM, Altman DG, Sauerbrei W, Taube SE, Gion M, Clark GM (2005) REporting recommendations for tumor MARKer prognostic studies (REMARK). Nat Clin Pract Oncol 2(8): 416-422.

Minami T, Jiang S, Schadler K, Suehiro J, Osawa T, Oike Y, Miura M, Naito M, Kodama T, Ryeom S (2013) The calcineurin-NFATangiopoietin-2 signaling axis in lung endothelium is critical for the establishment of lung metastases. Cell Rep 4(4): 709-723.

Monk BJ, Poveda A, Vergote I, Raspagliesi F, Fujiwara K, Bae D-S, Oaknin A, Ray-Coquard I, Provencher DM, Karlan BY, Lhommé C, Richardson G, Rincón DG, Coleman RL, Herzog TJ, Marth C, Brize A, Fabbro M, Redondo A, Bamias A, Tassoudji M, Navale L, Warner DJ, Oza AM (2014) Anti-angiopoietin therapy with trebananib for recurrent ovarian cancer
(TRINOVA-1): a randomised, multicentre, double-blind, placebocontrolled phase 3 trial. Lancet Oncol 15(8): 799-808.

Murukesh N, Dive C, Jayson GC (2010) Biomarkers of angiogenesis and their role in the development of VEGF inhibitors. Br J Cancer 102(1): 8-18.

Ohtsu A, Shah MA, Van Cutsem E, Rha SY, Sawaki A, Park SR, Lim HY, Yamada Y, Wu J, Langer B, Starnawski M, Kang YK (2011) Bevacizumab in combination with chemotherapy as first-line therapy in advanced gastric cancer: a randomized, double-blind, placebo-controlled phase III study. J Clin Oncol 29(30): 3968-3976.

Park JH, Park KJ, Kim YS, Sheen SS, Lee KS, Lee HN, Oh YJ, Hwang SC (2007) Serum angiopoietin-2 as a clinical marker for lung cancer. Chest 132(1): 200-206.

Rigamonti N, De Palma M (2013) A role for angiopoietin-2 in organ-specific metastasis. Cell Rep 4(4): 621-623.

Rigamonti N, Kadioglu E, Keklikoglou I, Wyser Rmili C, Leow CC, De Palma M (2014) Role of angiopoietin-2 in adaptive tumor resistance to VEGF signaling blockade. Cell Rep 8(3): 696-706.

Scholz A, Lang V, Henschler R, Czabanka M, Vajkoczy P, Chavakis E, Drynski J, Harter PN, Mittelbronn M, Dumont DJ, Plate KH, Reiss Y (2011) Angiopoietin-2 promotes myeloid cell infiltration in a beta(2)integrin-dependent manner. Blood 118(18): 5050-5059.

Schulz P, Fischer C, Detjen KM, Rieke S, Hilfenhaus G, von Marschall Z, Bohmig M, Koch I, Kehrberger J, Hauff P, Thierauch KH, Alves F, Wiedenmann B, Scholz A (2011) Angiopoietin-2 drives lymphatic metastasis of pancreatic cancer. FASEB J 25(10): 3325-3335.

Sfiligoi C, de Luca A, Cascone I, Sorbello V, Fuso L, Ponzone R, Biglia N, Audero E, Arisio R, Bussolino F, Sismondi P, De Bortoli M (2003) Angiopoietin-2 expression in breast cancer correlates with lymph node invasion and short survival. Int J Cancer 103(4): 466-474.

Sheridan C (2015) Amgen's angiopoietin blocker fails in ovarian cancer. Nat Biotechnol 33(1): 5-6.

Silha JV, Krsek M, Sucharda P, Murphy LJ (2005) Angiogenic factors are elevated in overweight and obese individuals. Int J Obes 29: 1308-1314.

Srivastava K, Hu J, Korn C, Savant S, Teichert M, Kapel SS, Jugold M, Besemfelder E, Thomas M, Pasparakis M, Augustin HG (2014) Postsurgical adjuvant tumor therapy by combining anti-angiopoietin-2 and metronomic chemotherapy limits metastatic growth. Cancer Cell 26(6): 880-895.

Tsoli M, Robertson G (2013) Cancer cachexia: malignant inflammation, tumorkines, and metabolic mayhem. Trends Endocrinol Metab 24: 174-183.

Van Cutsem E, de Haas S, Kang YK, Ohtsu A, Tebbutt NC, Ming Xu J, Peng Yong W, Langer B, Delmar P, Scherer SJ, Shah MA (2012) Bevacizumab in combination with chemotherapy as first-line therapy in advanced gastric cancer: a biomarker evaluation from the AVAGAST randomized phase III trial. J Clin Oncol 30(17): 2119-2127.

Volkova E, Willis JA, Wells JE, Robinson BA, Dachs GU, Currie MJ (2011) Association of angiopoietin-2, C-reactive protein and markers of obesity and insulin resistance with survival outcome in colorectal cancer. Br J Cancer 104(1): 51-59.

Wilke H, Muro K, Van Cutsem E, Oh SC, Bodoky G, Shimada Y, Hironaka S, Sugimoto N, Lipatov O, Kim TY, Cunningham D, Rougier P, Komatsu Y, Ajani J, Emig M, Carlesi R, Ferry D, Chandrawansa K, Schwartz JD, Ohtsu A. Group RS (2014) Ramucirumab plus paclitaxel versus placebo plus paclitaxel in patients with previously treated advanced gastric or gastro-oesophageal junction adenocarcinoma (RAINBOW): a double-blind, randomised phase 3 trial. Lancet Oncol 15(11): 1224-1235.

Zhang L, Yang N, Park JW, Katsaros D, Fracchioli S, Cao G, O’Brien-Jenkins A, Randall TC, Rubin SC, Coukos G (2003) Tumor-derived vascular endothelial growth factor up-regulates angiopoietin-2 in host endothelium and destabilizes host vasculature, supporting angiogenesis in ovarian cancer. Cancer Res 63(12): 3403-3412.

This work is published under the standard license to publish agreement. After 12 months the work will become freely available and the license terms will switch to a Creative Commons AttributionNonCommercial-Share Alike 4.0 Unported License.

Supplementary Information accompanies this paper on British Journal of Cancer website (http://www.nature.com/bjc) 